Document downloaded from:

http://hdl.handle.net/10251/145975

This paper must be cited as:

Morinigo-Sotelo, D.; Romero-Troncoso, R.; Panagiotou, P.; Antonino-Daviu, J.; Gyftakis, KN. (03-2). Reliable Detection of Rotor Bars Breakage in Induction Motors via MUSIC and ZSC Methods. IEEE Transactions on Industry Applications. 54(2):1224-1234.

https://doi.org/10.1109/TIA.2017.2764846

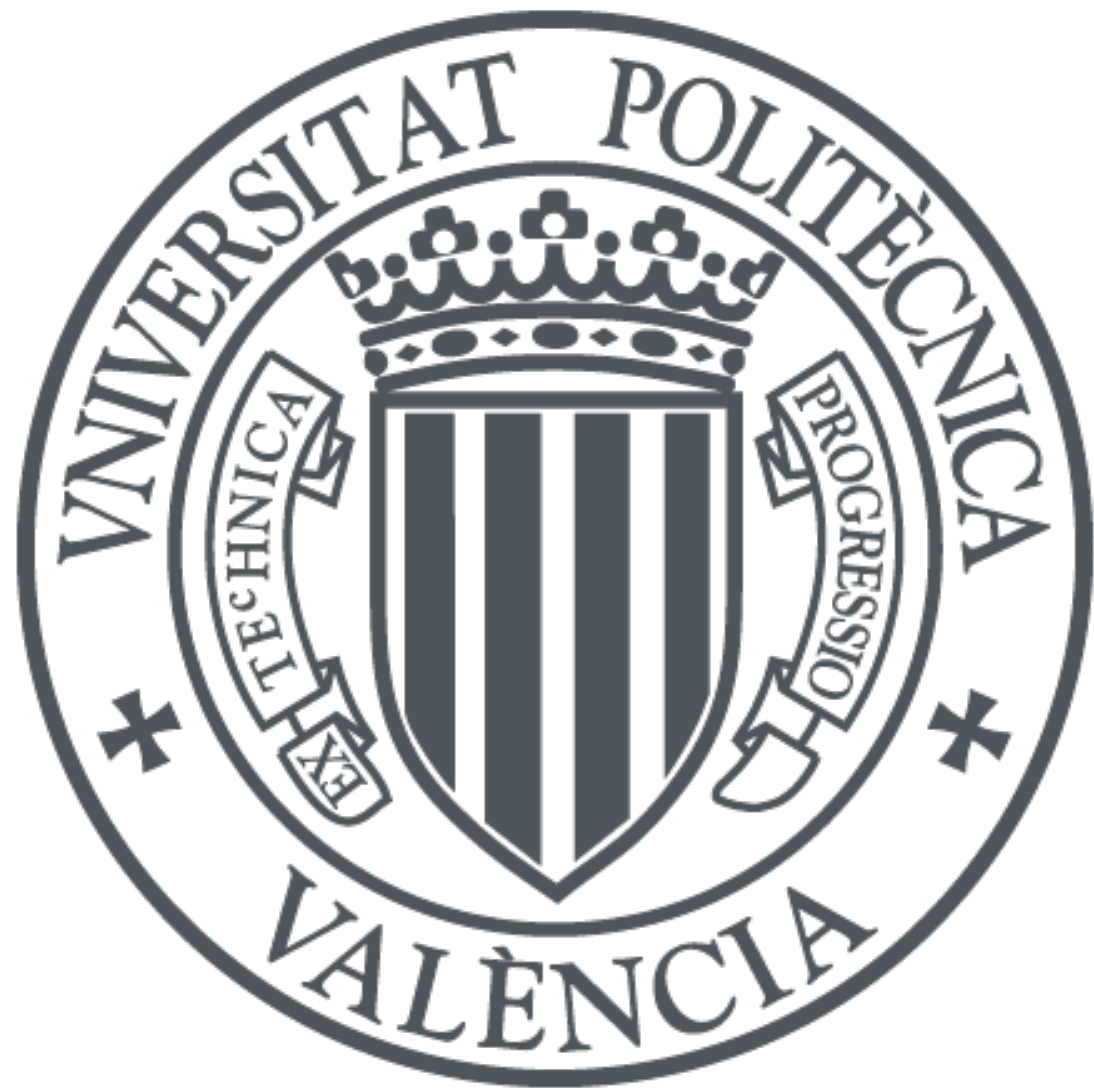

The final publication is available at

https://doi.org/10.1109/TIA.2017.2764846

Copyright Institute of Electrical and Electronics Engineers

Additional Information

"(c) 2018 IEEE. Personal use of this material is permitted. Permission from IEEE must be obtained for all other uses, in any current or future media, including reprinting/republishing this material for advertising or promotional purposes, creating new collective works, for resale or redistribution to servers or lists, or reuse of any copyrighted component of this work in other works" 


\title{
Reliable Detection of Rotor Bars Breakage in Induction Motors via MUSIC and ZSC Methods
}

\author{
D. Morinigo-Sotelo, Member, IEEE, R. J. Romero-Troncoso, Senior Member, IEEE, P. A. Panagiotou, \\ J. A. Antonino-Daviu, Senior Member, IEEE and K. N. Gyftakis, Member, IEEE
}

\begin{abstract}
Induction motors are used in a variety of industrial applications where frequent startup cycles are required. In those cases, it is necessary to apply sophisticated signal processing analysis methods in order to reliably follow the time evolution of the fault-related harmonics in the signal. In this paper, the zero-sequence current (ZSC) is analysed using the high-resolution spectral method of multiple signal classification (MUSIC). The analysis of the ZSC signal has proved to have several advantages over the analysis of a singlephase current waveform. The method is validated through simulation and experimental results. The simulations are carried out for a $1.1 \mathrm{MW}$ and a $4 \mathrm{~kW}$ induction motors under finite element analysis (FEA). Experimentation is performed on a healthy motor, a motor with one broken rotor bar, and a motor with two broken rotor bars. The analysis results are satisfactory since the proposed methodology reliably detects the broken rotor bar fault and its severity, both during transient and steady state operation of the induction motor.
\end{abstract}

Index Terms-Broken bar, Fault diagnosis, Induction motor, MUSIC, ZSC

\section{INTRODUCTION}

$\mathrm{T}$ HE induction motor condition monitoring area has drawn a prominent attention over recent decades [1]-[3]. This is due to the extensive use of these machines in industry (more than $90 \%$ of the rotating electrical machines are either cage or wound rotor induction motors) as well as to their paramount importance in most of the processes where they operate [4]. Although these machines have been deeply studied in the literature, it is a fact that the accurate determination of their health condition is not always straightforward, and that there are many industrial applications where it may be especially difficult [5]-[8]. Note also that, in many cases, it is not enough to detect the presence of a certain fault or anomaly, but it also becomes

This work was supported in part by the Spanish 'Ministerio de Economía y Competitividad' (MINECO) and FEDER program in the framework of the 'Proyectos I+D del Subprograma de Generación de Conocimiento, Programa Estatal de Fomento de la Investigación Científica y Técnica de Excelencia' (ref: DPI2014-52842-P)."

Daniel Morinigo-Sotelo is with the University of Valladolid, Spain, and with the HSPdigital Research Group, México. (e-mail: dmorinigo@hspdigital.org)

Rene J. Romero-Troncoso is with the CA Telematica at DICISUniversity of Guanajuato, Mexico and with HSPdigital Research Group, México. (e-mail: troncoso@hspdigital.org)

Panagiotis A. Panagiotou is with Research Centre for Mobility and Transport, Coventry Unviersity.

Jose Antonino-Daviu is with the Universitat Politècnica València, Instituto Tecnológico de la Energía (ITE), camino de Vera s/n, 46022 Valencia, Spain. (e-mail: joanda@die.upv.es).

K. N. Gyftakis is with the School of CEM and with the Research Centre for Mobility and Transport, Coventry University, UK. (e-mail: k.n.gyftakis@ieee.org). necessary to determine its severity with accuracy, in order to be able to evaluate, with enough criteria, the necessity of adopting proper maintenance actions and decide an eventual interruption of the process [1], [4]. As a consequence, it is easy to understand that a continuous worldwide interest exists, both in industry and in academia, in this challenging scientific field.

Rotor faults constitute about $10-15 \%$ of total induction motor faults [4]. However, this occurrence rate is higher for large motors which are indeed the most costly, critical and difficult to repair [9]. Moreover, although the physical mechanisms leading to a rotor fault vary depending on the manufacturing type, application, and working environment, among others [4], [8], [10], it has been proven that industrial applications with frequent transients (heavy startups, abrupt load variations, plugging transients) are more likely to cause rotor damages due to large temperature gradients and high stresses during transient operation [10]. Studies have shown that the breakage of a bar leads to overcharge the adjacent bars, which are more likely to break next [11]. However, some industrial users have also reported the breakage of bars in non-adjacent positions in the rotor cage [12]-[13]. On the other hand, although, in general, a broken rotor bar does not lead to an immediate catastrophic machine failure, this is not always the case. It has been shown in the past that the protrusion of broken rotor bars or the detachment of small fragments after the breakage can lead to a damage of the stator end winding resulting in forced motor outages [14]. Furthermore, it is deduced that prompt and reliable diagnosis is a need in order to detect the fault at an incipient stage.

There is a vast literature on induction motor broken rotor bar detection. Many authors have proposed diverse methods relying on the analysis of different motor quantities for the diagnosis of such fault. In this regard, vibration data analysis has been employed to this end, despite this technique has proven to be better suited for the detection of mechanicalrelated failures [11, 15]. Although other alternatives have been recently proposed such as those based on the study of torque [16]-[17], speed [18], flux [19]-[21], electrical power [22]-[23] or even ultrasound data [24], the most extended method for the diagnosis of rotor damages relies on the analysis of motor currents. In this context, the most widespread approach is the well-known Motor Current Signal Analysis (MCSA), which relies on the processing of stator current with the fast Fourier transform (FFT) and the subsequent evaluation of the fault components amplitudes in the resulting frequency spectrum [4].

In these recent years, different constraints of MCSA have been reported by different authors. As a consequence, novel 
methods based either on the most sophisticated and optimized analysis of stationary currents [25] or the study of motor currents during transient operation $[6,26]$ have been proposed. In this context, a vast diversity of signal processing, transforms and analysis tools have been proposed, such as Park's vector-related approaches [27]-[28], Hilbert transform [29], wavelet-related variants [6], [30], [31]-[32], Hilbert-Huang transformations [33]-[34], WignerVille and Choi-Williams Distributions [35], among many others. This has come together with the proliferation of artificial intelligence and pattern recognition algorithms which have been successfully employed, especially for automatic fault classification purposes [3].

Recently, a promising approach has been introduced in the induction motor fault diagnosis area. This approach relies on the study of the Zero-Sequence Current (ZSC). Some very recent works have proven the suitability of the tool to detect rotor failures, even at no-load or low-load applications, due to its relation to the saturation level of the motor, bringing in this regard notorious advantages versus MCSA [36]. Moreover, the analysis of the ZSC reveals other faults such as the static eccentricity in the principal slot harmonic (PSH) of the diagnosed motor. This is not feasible with the classical analysis of a single-phase current [37]. Finally, it offers a generalized diagnosis potential as it has been shown in [38]. Hence, in spite of its measurement requirements, the study of the ZSC may bring decisive information for a more reliable determination of the motor condition.

Most of the recent methods proposing the use of the ZSC for diagnosis purposes have been focused on the analysis of the signal during steady-state regime, by applying the classical FFT. These methods suffer from the inherent disadvantages of the FFT, such as the spectral leakage, quantization errors as well as low-frequency resolution. An interesting possible alternative, following the same approach used when analysing phase currents, is to extend the ZSC analysis to transient motor operation [39]. In this context, some available time-frequency tools such as the short-time Fourier transform (STFT) methods may have a poor timefrequency resolution that prevents the observation of lowenergy harmonics close to high-energy harmonics, as the main component. Therefore, high-resolution methods are necessary for a successful extension of the ZSC analysis to transient regimes. In this regard, Multiple signal classification (MUSIC) is a technique that belongs to the family of sub-space spectral estimation methods, which is particularly suited for the analysis of noisy signals [40]. It offers an excellent resolution with non-stationary signals whereas it requires only a short time window [41].

In this paper, for the first time, a new ZSC-based methodology is proposed aiming at the reliable fault detection of broken rotor bars in induction motors under transient and steady-state operation. The proposed method is based on the analysis of the ZSC spectrum during a start-up and the subsequent steady-state. The analysis is performed with the application of the MUSIC algorithm to extract the time-dependant behaviour of the ZSC fault-related harmonics. To prove the general validity of the approach, the method is applied to motors with very different sizes and operating conditions: firstly the method is applied to a large industrial 1.1MW induction motor under healthy condition and one broken rotor bar, with the use of the Finite Element Analysis (FEA). Then a $4 \mathrm{~kW}$ induction motor is also studied with FEM while starting under load conditions. The extensive FEA simulations are entirely new contributions with respect to [39]. Moreover, they allow for the validation and generalization of the proposed method despite the size and electromagnetic characteristics of the tested motor.

Then, experimentation is performed in the laboratory on $1.1 \mathrm{~kW}$ motors under different fault conditions (healthy motor, motor with one broken rotor bar and motor with two broken rotor bars). The results prove to be satisfactory in all considered motors, and the fault is reliably detected, as well as its severity level. The method itself proves to be superior to the well-established traditional monitoring and analysis of a single stator current for low time transients.

\section{THEORETICAL BACKGROUND}

\section{A. The Zero-Sequence Current in Induction Motors with Broken Rotor Bars}

The ZSC can be monitored in either delta-connected or star-connected, with the neutral connected, induction motors. From the theory of classical machines, the ZSC consists of the direct sum of the three-phase instantaneous currents:

$$
i_{Z S C}=i_{a}+i_{b}+i_{c}
$$

This means that in the case of delta-connected induction motors it is required to monitor all three phase currents independently and then sum the monitored waveforms. Furthermore, in the case of star-connected induction motors, one can monitor the neutral current, so only one current sensor is required. If the neutral is not connected, then it is evident that the zero-sequence current is zero and thus cannot be monitored for diagnosis.

Due to the stator magnetomotive forces (MMF) higher harmonic index due to supply harmonics, as well as the iron core saturation level, the fundamental harmonic of the ZSC is given by Eq. (2) as follows:

$$
I_{Z S C_{-} 1}=3\left\lfloor I_{p h_{-} 3} \cos \left(3 \omega_{s} t\right)+I_{s a t_{-} 3} \cos \left(3 \omega_{s} t+\varphi_{s a t}\right)\right\rfloor
$$

where:

$I_{z s c_{-} l}$ : fundamental ZSC harmonic

$I_{p h_{-} 3}:$ third MMF phase current harmonic

$I_{\text {sat_3 }}$ : third phase current harmonic due to saturation

$\omega_{s}$ : radial supply frequency

$\varphi_{\text {sat: }}$ saturation phase angle

$t$ : time

When there is a broken bar fault, two opposite waves are created in the rotor rotating with $s \cdot f_{s}$ and $-s \cdot f_{s}$, being $f_{s}$ the fundamental supply frequency and $s$ the motor slip. The third stator harmonic $3 f_{s}$ induces eddy currents to the rotor. Those superimposed eddy currents have frequency $3 s f_{s}$ and produce an electromagnetic torque which forces the rotor to rotate at a speed of $3(1-s) \cdot f_{s}$. So, the $s \cdot f_{s}$ and $-s \cdot f_{s}$ travelling waves interact with the rotational speed $3(1-s) \cdot f_{s}$ and induce 
in the stator winding the characteristic broken rotor bar frequencies: $3 \cdot f_{s}-2 \cdot s \cdot f_{s}$ and $3 \cdot f_{s}-4 \cdot s \cdot f_{s}$. A second mechanism co-exists with the aforementioned. The $3 \cdot f_{s}$ stator rotating magnetic field induces eddy currents in the rotor with a $3 s \cdot f_{s}$ frequency. When there is present a broken bar fault, there appears another couple of opposite traveling waves with frequencies $3 \cdot s \cdot f_{s}$ and $-3 \cdot s \cdot f_{s}$. The first one is added to the $3(1-s) \cdot f_{s}$ rotor speed and thus it rotates along to the $3 \cdot f_{s}$ stator magnetic field without inducing any broken bar fault signatures to the stator winding. However, the latter $-3 \cdot s \cdot f_{s}$ induces $3 \cdot f_{s}-6 \cdot s \cdot f_{s}$ harmonics to the stator winding. It is worth noticing that due to the speed ripple effect, harmonics at $3 \cdot f_{s}+k \cdot s \cdot f_{s}, k=2,4,6$ are also expected, especially at greater fault-severity levels.

\section{B. The MUSIC algorithm}

The MUSIC algorithm, which was introduced at the same time in [42] and in [43], belongs to the family of methods based on the decomposition of the observation space into signal and noise subspaces. These methods have the highresolution property. MUSIC considers that a signal $x(t)$ is a sum of $P$ complex sinusoids in an additive white noise:

$$
x(t)=\sum_{k=1}^{P} A_{k} e^{j\left(2 \pi t_{k} t+\varphi_{k}\right)}+w(t)
$$

where $A_{k}$ is the amplitude, $f_{k}$ is the frequency, $\varphi_{k}$ is the phase of the $k_{t h}$ space vector and $w(t)$ is white noise, and $P$ is also known as the MUSIC order. The sinusoid amplitude and frequency are not random and unknown. The phases of the sinusoids are uncorrelated random variables, uniformly distributed over the interval $[-\pi, \pi]$.

The power spectrum of $x(t)$ consists of a set of $P$ impulses of area $2 \pi\left|A_{k}\right|$ at frequencies $f_{k}$ for $k=1,2, \ldots, P$, plus the power spectrum of the additive noise $w(t)$. Based on the orthogonality of the signal and noise subspaces, the MUSIC pseudo-spectrum $P_{\text {MUSIC }}$ of the current space vector is given by the following frequency estimation function [40]:

$$
P_{\text {MUSIC }}(f)=\frac{1}{\sum_{i=P+1}^{M}\left|\bar{e}_{i}^{H} \bar{V}_{i}\right|^{2}}
$$

where $\bar{v}_{i}$ is the noise eigenvector and $\bar{e}_{i}^{H}$ is the signal vector defined as $\bar{e}_{i}^{H}\left(f_{i}\right)=\left[1, e^{-j 2 \pi f_{i}}, \mathrm{~K}, e^{-j 2 \pi f_{i}(M-1)}\right]$. The Eq. 4 shows a maximum when, for a certain $f_{k}$ truly present in the signal, the signal and noise subspaces projections are zero.

\section{Finite ElEMENT ANALYSIS}

FEA is the ideal tool to study the effectiveness of the proposed method excluding manufacturing tolerances, inherent motor asymmetries and measuring equipment errors. Furthermore, the actual motor geometry and non-linear properties of the materials are taken into consideration thus the FEA simulation results come very close to reality.

\section{A. The case of a 6-pole, $6.6 \mathrm{kV}, 1.1 \mathrm{MW}$ induction motor}

In this section, a large industrial induction motor has been simulated and studied with MagNet from Infolytica. The studied motor is a 6-pole, $6.6 \mathrm{kV}, 1.1 \mathrm{MW}, 50 \mathrm{~Hz}$ cage induction motor. The FEA model of the motor has been built based on the manufacturer blueprints and material characteristics. The rotor of the real motor is fabricated from copper bars where the cage is un-skewed, which is usual for motors of this size. Moreover, the copper bars are electrically isolated from the iron core. So, if there is a broken rotor bar then the inter-bar currents are negligible, and this plays an important role when simulating the faulty case of the motor with FEA.

In a real broken rotor bar case, two phenomena happen depending on the rotor type. In cast aluminium motors the rotor bars are not isolated from the iron core, and inter-bar currents are free to circulate due to the iron's conductivity. This means that there is a low current flowing from ring to ring through the broken bar and which produces some useful torque. However this does not exist in fabricated from copper cages. That is because there is insulation between the bars and the rotor iron core which forbids the inter-bar cross currents. However, the broken bar is still in place and has a conductivity. This will result to eddy currents in the bar which do not produce torque but just heat. However, in large motors due to the extremely low slip, the impact of those broken bar eddy currents can be neglected.

Usually, cast aluminium rotors have skewed bars which further enhance the inter-bar currents, which have an adverse impact on the diagnosis of broken rotor bars because they allow the current flow through the iron thus negatively influence the fault severity estimation. Despite that, in the case of the motor under investigation, the rotor bars are isolated from the iron and they are un-skewed, so no significant inter-bar currents exist. This is why the broken bar has been practically considered an open circuit in this analysis. This has been accomplished by adding a very high resistance $(1 \mathrm{MOhm})$ in series with the broken rotor bar.

Motors of this size usually start without load, accelerate until low-load speed and then the load is mechanically coupled. This is due to the very low rotor resistance which leads to low starting torque. So, both healthy and faulty motors have been simulated to start and accelerate to steady state without mechanical load. Only a relatively small load exists $(50 \mathrm{Nm})$ to account for friction. Fig. 1 illustrates the spatial distribution of the magnetic flux density amplitude for both studied cases at $\mathrm{t}=300 \mathrm{~ms}$ which is practically during the startup transient. It is clear that the skin effect impact is strong due to the high rotor frequency. Thus the magnetic flux does not penetrate deep into the rotor core but stays on the surface. Furthermore, in the faulty case it is clear that there is some local saturation involved at the teeth adjacent to the broken rotor bar.

A similar investigation at steady state did not offer significant results. This is because the rotor frequency is almost zero and the skin effect weak. So, the flux penetrates deep in the rotor core. As a result, the magnetic asymmetry caused by a single bar proved to be very small. This was also due to the low rotor current since the motor was simulated to operate at low load.

The combination of the skin effect and the high starting rotor current make the diagnosis of rotor faults during the transient of starting very appealing for industrial practice. 
The ZSC waveforms for healthy and faulty motors have been extracted for the whole motor simulated operation and presented in Fig. 2. It can be seen that although the motor accelerates without mechanical load the starting time is relatively long due to high rotor inertia. The healthy motor reaches steady state after $1.45 \mathrm{~s}$ whereas the faulty after $1.8 \mathrm{~s}$.

It is to be noted that, during starting the ZSC waveform of the motor with a broken rotor bar (Fig. 2-b) experiences oscillations unlike the smooth starting of the healthy motor (Fig. 2-a). This is the result of multiple combined mechanisms. Firstly, the rotor current is maximum during starting. Simultaneously, the frequency of the rotor current is maximum at zero speed. This implies significant skin effect and weak magnetic flux penetration in the rotor body. The above two remarks combined lead to stronger distortion of the magnetic field due to the broken rotor bar. Furthermore, it was shown in the past that more harmonics are generated in the stator currents due to the speed ripple effect [44]. The overall combination of the above distortions Together with a minor impact of the higher local to the broken rotor bar iron core saturation leads to the increased oscillations of the ZSC during starting.

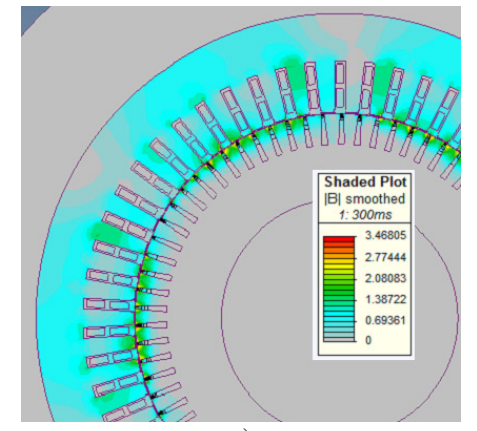

a)

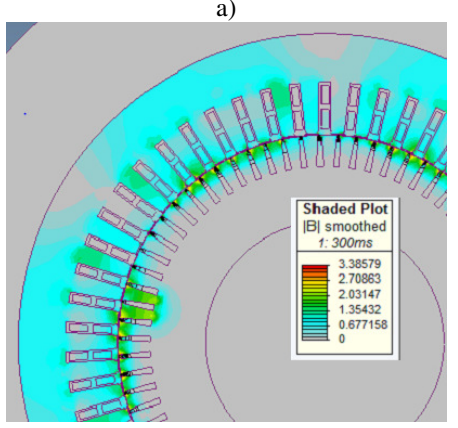

b)

Fig. 1. Spatial distribution of the amplitude of the magnetic flux density during starting (at $\mathrm{t}=300 \mathrm{~ms}$ ) for: $\mathrm{a}$ ) healthy and $\mathrm{b}$ ) faulty motor.

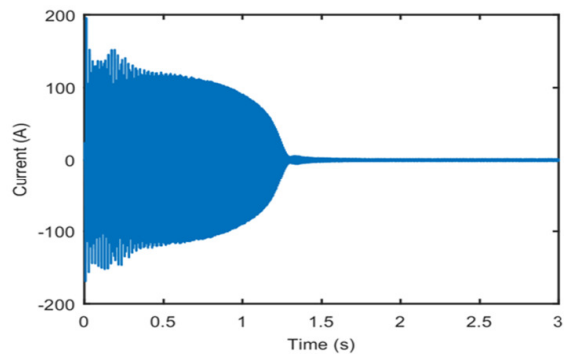

a)

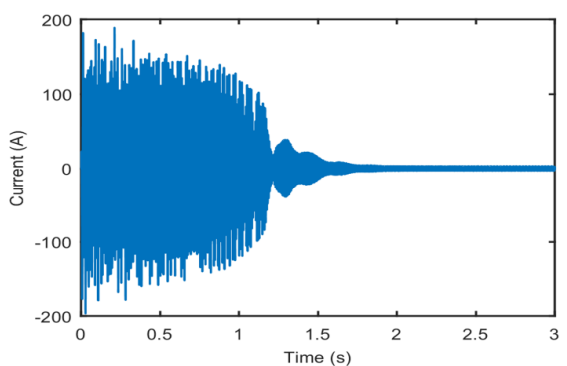

b)

Fig. 2. The ZSC waveforms for: a) healthy and b) faulty induction motor (FEA results).

The original sampling frequency from FEA has been 10 $\mathrm{kHz}$. Both data sets have been resampled to a final sampling frequency of $1024 \mathrm{~Hz}$. Then, the pseudospectrum is estimated using the MUSIC algorithm. The results are presented in Fig. 3. The MUSIC order necessary to produce such spectrograms was 180 , with a window length of 0.2 seconds. It can be seen that the healthy motor has limited harmonic index easily predictable by analytical formulae. The fundamental ZSC harmonic at $150 \mathrm{~Hz}$ is easily observed. Moreover, the stator current fundamental harmonic at $50 \mathrm{~Hz}$ can also be seen. The $50 \mathrm{~Hz}$ harmonic exists in the motor because it is not a PSH induction motor. Moreover, a rotor slot related harmonic is observed close to $400 \mathrm{~Hz}$. The expected $9^{\text {th }}$ harmonic at $450 \mathrm{~Hz}$ is quite strong during the transient operation but significantly weakens at low load steady state operation.

On the other hand, the spectrogram is rich in harmonics for the case of the motor with a broken rotor bar. The three harmonics previously mentioned for the healthy motor are still there. Yet, now the $450 \mathrm{~Hz}$ harmonic is really strong even at steady state. This is due to the increased saturation level of the motor at low load operation. Furthermore, the well-known broken bar fault related sidebands located at: $3 \cdot f_{s}-2 \cdot s \cdot f_{s}$ and $3 \cdot f_{s}-4 \cdot s \cdot f_{s}$ are very clear (arrows at the bottom left corner of Fig. 3-b). The latter creates a V-shape trajectory while the speed of the motor increases. Moreover, since the rotor magnetic field is now asymmetrical, it creates a weak but noticeable harmonic at the mechanical frequency $20 \mathrm{~Hz}$. The remaining newly appeared harmonics are related to the mechanical speed and the rotor slot number.

The FEA results prove to be interesting and point out harmonic trajectories that can reliably reveal the broken rotor bar fault in large industrial induction motors during the startup transient.

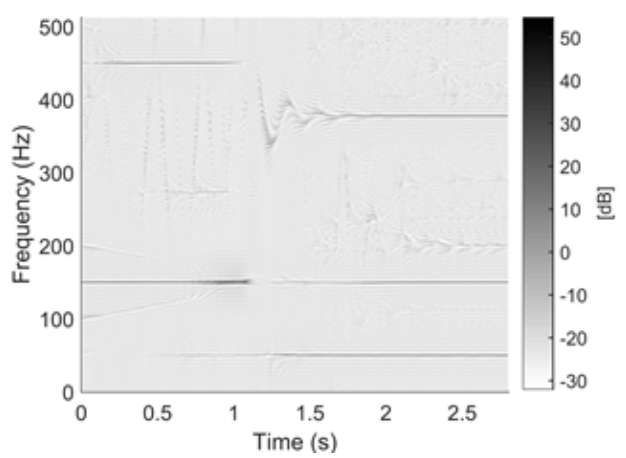

a) 


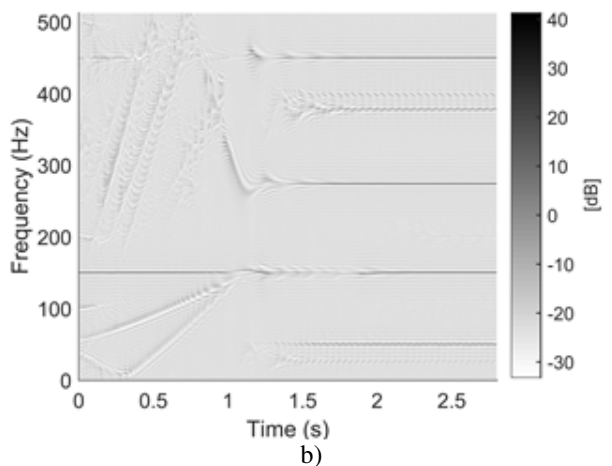

Fig. 3. MUSIC spectrogram of: a) the healthy motor and b) the motor with a broken rotor bar at no load.

\section{B. The case of a 4-pole, $400 \mathrm{~V}, 4 \mathrm{~kW}$ induction motor}

In this section, similar procedure to the previous section $\mathrm{A}$ has been followed. However, the motor under investigation is a smaller motor with aluminium cast cage rotor. The FEM model has been built based on the manufacturer's blueprints as well. Same as before, a $1 \mathrm{MOhm}$ resistance has been connected in series with a bar to account for the breakage. The motor has been simulated to start under applied mechanical load $15 \mathrm{Nm}$. The ZSC as well as the line current waveforms have been extracted from the healthy and faulty cases. The pseudospectrum is estimated again using the MUSIC algorithm with a 0.1 seconds window length. The results are illustrated in the following Fig. 4 and 5.

The starting time of the $4 \mathrm{~kW}$ motor is significantly lower than the $1,1 \mathrm{MW}$ one, considering also that the former starts coupled to a load. In Fig. 4-b, the expected broken bar fault signatures are detected. However, no fault related signatures can be identified when looking at the line current spectrogram in Fig. 5. This implies the diagnostic superiority of the ZSC over the traditional monitoring of a single stator current. This superiority lies in the fact that the ZSC fundamental harmonic is 3 times greater than the line current's. As a result, 3 times more periods are monitored in the case of the ZSC than the line current, thus significantly improving the resolution of the MUSIC algorithm.

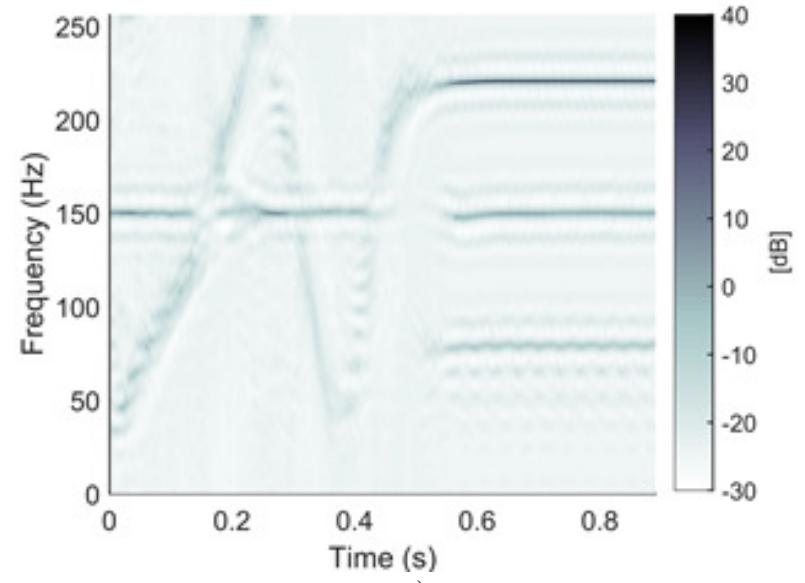

a)

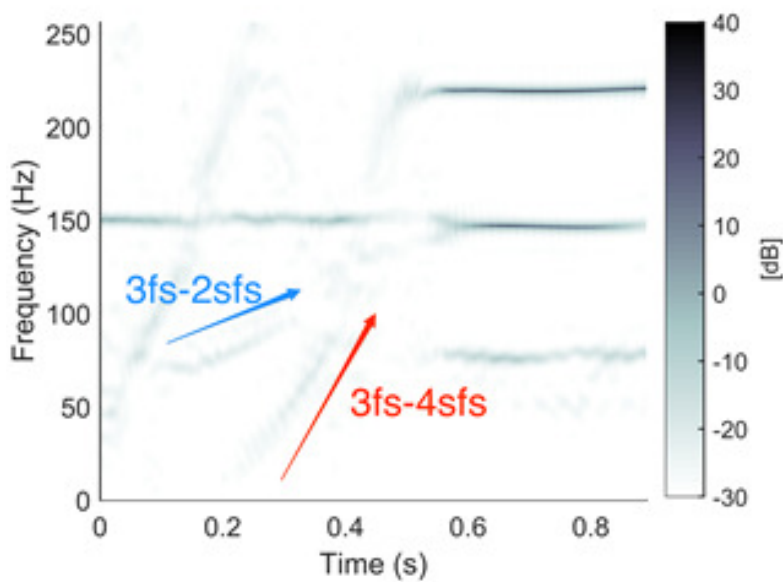

b)

Fig. 4. MUSIC spectrogram of the ZSC of: a) the healthy motor and b) the $4 \mathrm{~kW}$ motor with a broken rotor bar under $15 \mathrm{Nm}$ load.

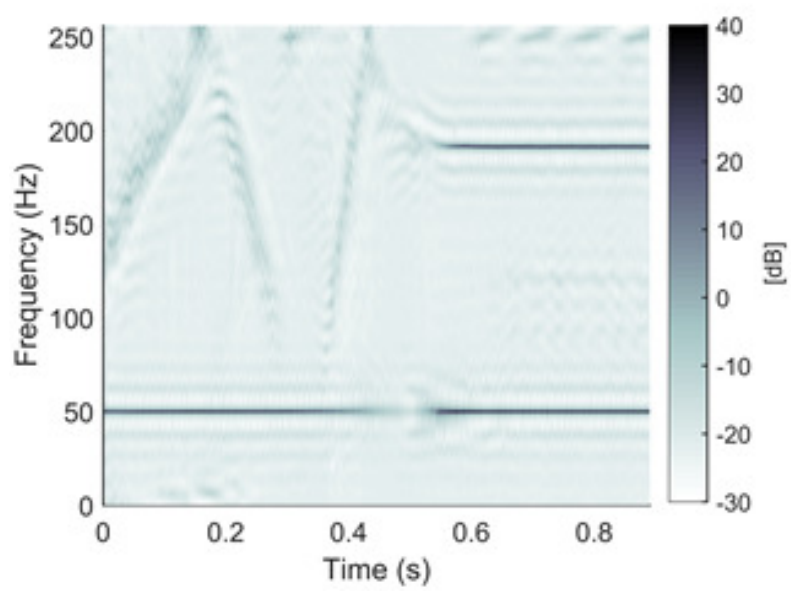

a)

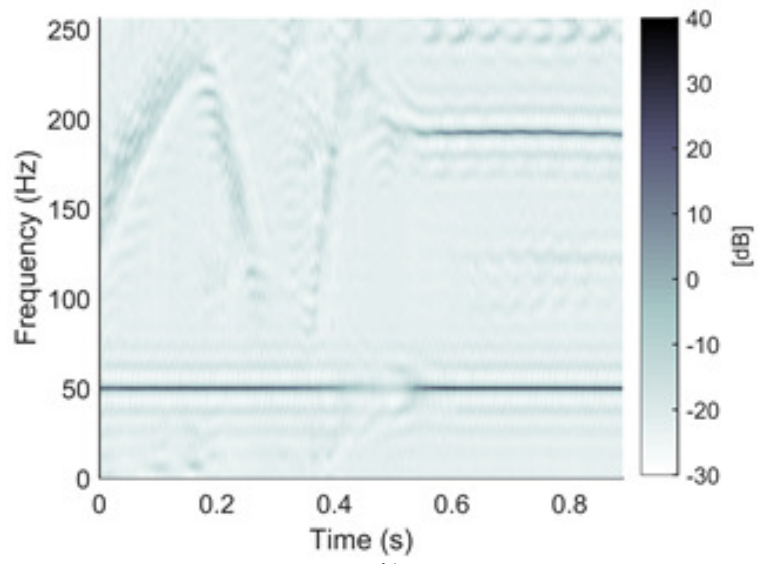

b)

Fig. 5. MUSIC spectrogram of the line current of: a) the healthy motor and b) the $4 \mathrm{~kW}$ motor with a broken rotor bar under $15 \mathrm{Nm}$ load.

\section{EXPERIMENTAL TESTING SETUP}

Experimental tests are carried out using a $1.1 \mathrm{~kW}$, 4-pole induction motor. Table I shows the rated characteristics of this motor. The motor is coupled to a DC machine that acted as the mechanical load. The different load levels are obtained by varying the excitation current of the DC machine. The 
supply voltage of the tested motor could be easily changed with the aid of an autotransformer. Fig. 6-a shows a picture of the test bench.

Three different motor conditions are tested: healthy state, motor with one broken rotor bar and motor with two adjacent broken rotor bars. The bar breakages were forced by drilling holes in the corresponding bars at their junction point with the short-circuit end-ring. Each drilling was carried out in such a way that the complete breakage of the corresponding bar is guaranteed. Different motor startups are developed at different voltage-supply levels.

In each test, the three phase currents are acquired during the motor startup by using Fluke i3000s flexible current clamps, connected to a waveform recorder (YOKOGAWA DL-850). The clamps are based on Rogowski coils that are suited for the measurement of large motor currents but can be also employed for measuring low currents with enough resolution. Fig. 6-b shows a detail of the current clamps. The signals are captured at a sampling rate of $5 \mathrm{kHz}$ and the register length is 100 seconds, which guarantees the acquisition of the whole startup as well as a significant portion of the steady-state regime. The current signals are initially stored in the recorder and afterwards transferred to a computer, where the ZSC is computed and further analyzed.

TABLE I

INDUCTION MOTOR CHARACTERISTICS

\begin{tabular}{|l|l|}
\hline Rated Power & $1.1 \mathrm{~kW}$ \\
\hline Rated frequency & $50 \mathrm{~Hz}$ \\
\hline Rated Voltage & $230 \mathrm{~V}$ \\
\hline Rated primary current & $4.5 \mathrm{~A}$ \\
\hline Rated speed & $1410 \mathrm{rpm}$ \\
\hline Rated slip & 0.06 \\
\hline Stator windings connection & Delta \\
\hline Number of pole pairs & 2 \\
\hline Number of rotor bars & 28 \\
\hline Number of stator slots & 36 \\
\hline
\end{tabular}

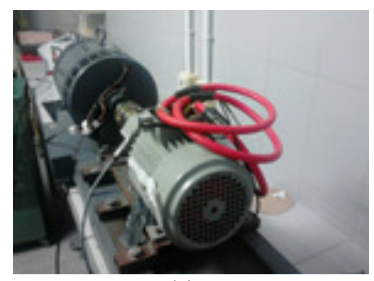

(a)

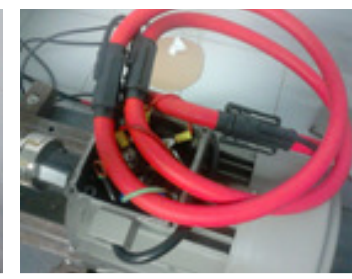

(b)
Fig. 6. Experimental test bench: a) motor-load bench and b) the current clamps configuration.

\section{EXPERIMENTAL RESULTS}

In this section, the experimental results are presented. Nine currents containing the startup transient and the subsequent steady-state have been analyzed. The ZSC is calculated from the three phase currents of the motor, acquired in each test. The ZSC is preprocessed by resampling to a final $1024 \mathrm{~Hz}$ sampling frequency and then filtered through a low-pass filter with a cut-off frequency of $200 \mathrm{~Hz}$. Afterwards, the pseudospectrum is estimated using MUSIC.

MUSIC provides a spectrogram of the ZSC for every measured induction motor case. So, Figs. 7 to 15 depict the spectrograms of the nine ZSC cases. The MUSIC order used to analyze each ZSC is indicated in the figure label. This parameter is determined experimentally for each analyzed signal. The window length is the same for all cases and it is set to 0.20 s. A window overlap of one sample is used in all cases.

Figs. 7-9 depict the results of the three condition cases with the motor operating at no load. The analysis of the healthy motor spectrogram (Fig. 7) offers some interesting characteristics. Firstly, the fundamental ZSC current harmonic at $150 \mathrm{~Hz}$ is very clear. At the same time, the fundamental phase current harmonic at $50 \mathrm{~Hz}$, due to some level of 3-phase supply unbalance, is also strong. The supply imbalance is also verified by the existence of an important $2 s f s$ component at $100 \mathrm{~Hz}$. The inherent mixed-eccentricity harmonic close to $25 \mathrm{~Hz}$ is also present. Finally, a V-shape is observed at $150 \mathrm{~Hz}$ and it drops to $50 \mathrm{~Hz}$. In Fig. 9, it is shown the spectrogram of the motor at no-load and with two broken bars.

If it is compared with the healthy case (Fig. 7), it is observed supplementary information. A second V-shape appears at $150 \mathrm{~Hz}$ and it drops down to $0 \mathrm{~Hz}$. The energy close to the ZSC fundamental seems increased because the broken bar fault signatures are located very close to the 150 Hz. Noticeably, in the case of the two broken bars (Fig. 9), the inherent mixed-eccentricity harmonic close to $125 \mathrm{~Hz}$ appears. Moreover, Fig. 8 illustrates the spectrogram of the motor with a broken rotor bar and operating at no load. It is anticipated the results observed in the case of 2 broken rotor bars (Fig. 9), but with a lower energy level. Even at no load, the energy of the fault related harmonics increases during the startup transient.

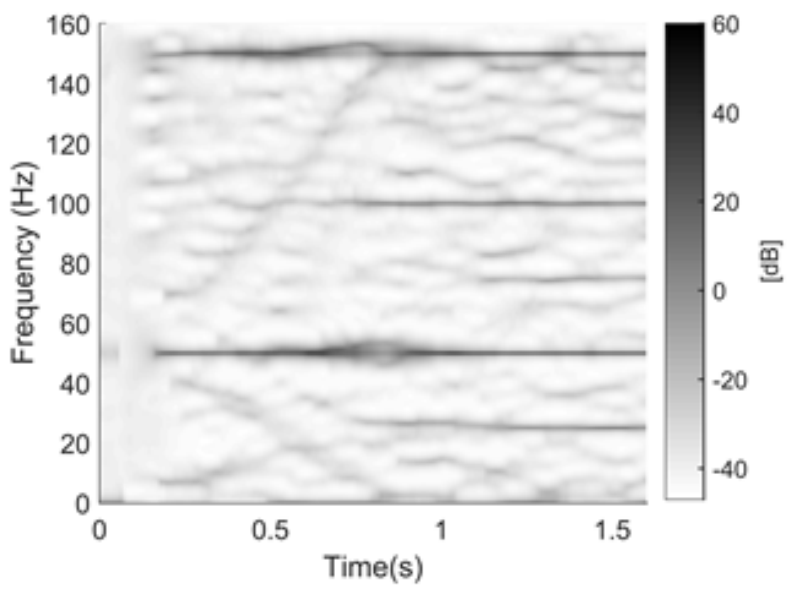

Fig. 7. MUSIC (order 36) spectrogram of the motor in healthy condition and at no load. 


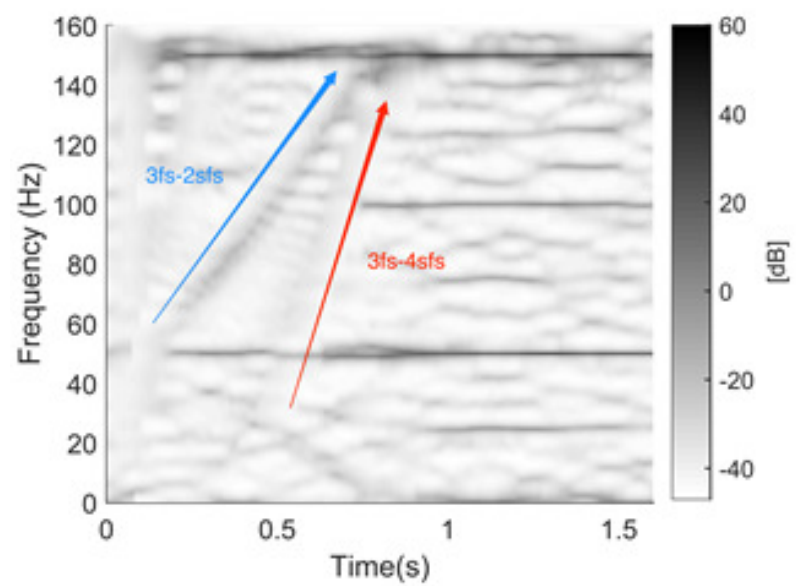

Fig. 8. MUSIC (order 40) spectrogram of the motor with 1 broken rotor bar and at no load.

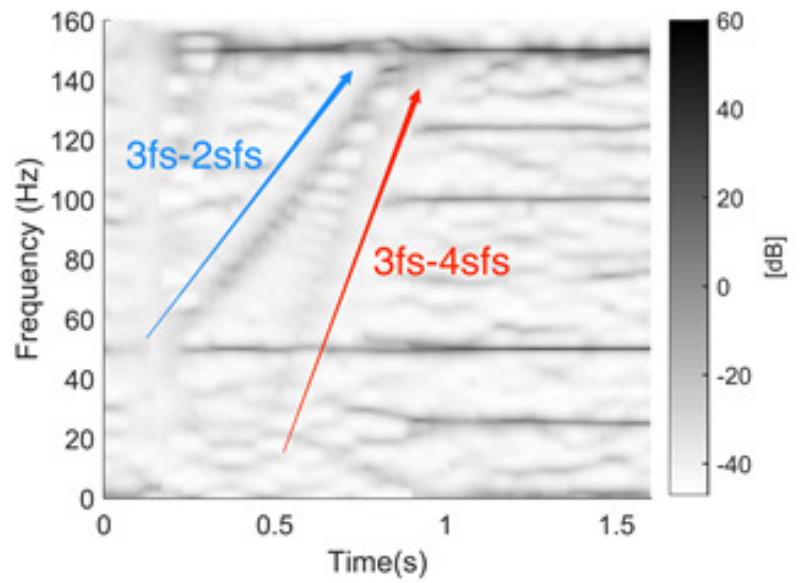

Fig. 9. MUSIC (order 39) spectrogram of the motor with 2 broken rotor bars and at no load.

The MUSIC spectrograms of the cases where the motor is at half-load are depicted in Figs 10-12. The healthy motor shows a behavior very similar to the no load case (Fig. 10). The MUSIC spectrogram of the motor with 1 broken rotor bar (see Fig. 11) shows a second V-shape trajectory, while the $3 \cdot f_{s}-2 \cdot s \cdot f_{s}$ and $3 \cdot f_{s}-4 \cdot s \cdot f_{s}$ sidebands are clearly visible and with a high-energy amplitude. Fig. 12 shows the MUSIC spectrogram of the induction motor case with 2 broken rotor bars.

A second $\mathrm{V}$-shape trajectory can be recognized and the ZSC sidebands around the $150 \mathrm{~Hz}$ are identified with high energy, as in the case of one broken bar. Additionally, the inherent mixed-eccentricity harmonic close to $125 \mathrm{~Hz}$ increases. Finally, the left sideband of the inherent mixedeccentricity harmonic close to $25 \mathrm{~Hz}$ increases also.

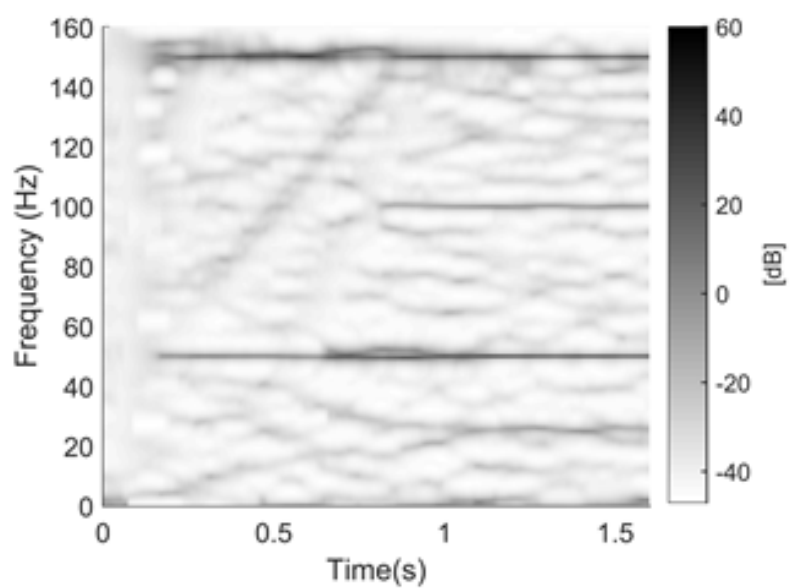

Fig. 10. MUSIC (order 38) spectrogram of the motor in healthy condition and at half load.

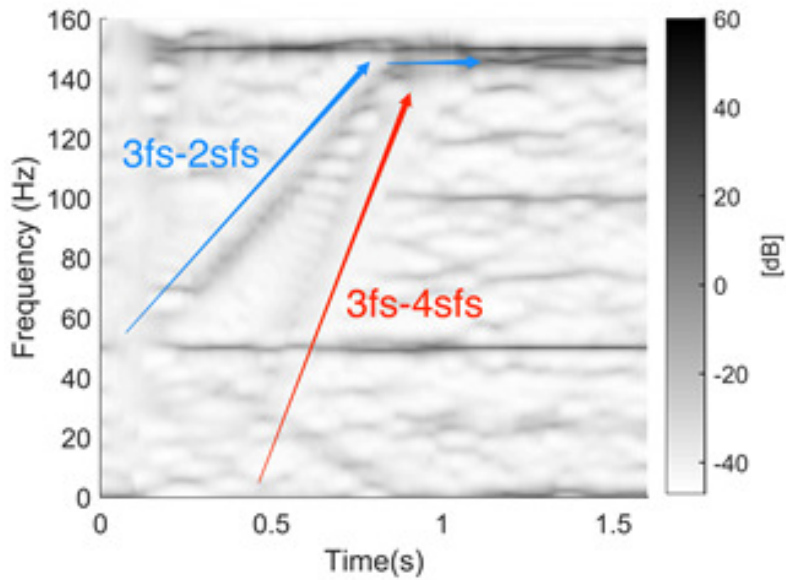

Fig. 11. MUSIC (order 38) spectrogram of the motor with 1 broken rotor bar and at half load.

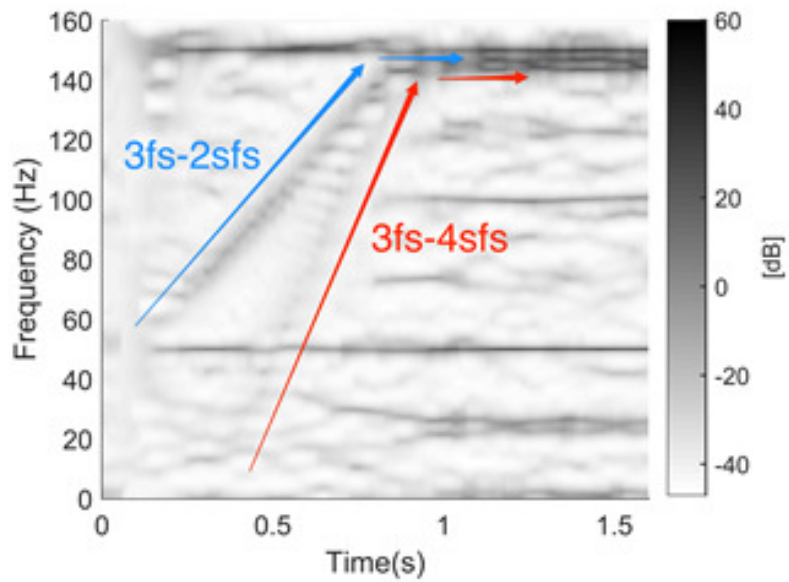

Fig. 12. MUSIC (order 44) spectrogram of the motor with 2 broken rotor bars and at half load.

Finally, the results of motor operating at full load are shown in Figs 13-15. At full load, the healthy motor displays two V-shape trajectories in the MUSIC spectrogram (see Fig. 13). Yet, none of them drops down to $0 \mathrm{~Hz}$.

The ZSC sidebands are visible, possibly because of 
inherent rotor asymmetries and shaft-load misalignment. The left sideband of the inherent mixed-eccentricity harmonic close to $25 \mathrm{~Hz}$ can also be observed, but this may be related to the aforementioned asymmetries and not the broken bar fault. In both faulty cases, the second V-shape trajectory drops down to $\mathrm{OHz}$ (see Fig. 14 and 15). It is also noticeable in Fig. 14 for 1 broken rotor bar that the $3 \cdot f_{s}-6 \cdot s \cdot f_{s}$ band appears.

The MUSIC spectrogram shows excellent diagnostic capabilities when the motor with 2 broken rotor bars is at full load (see Fig. 15). Besides, in the above-mentioned signatures, it is increased the energy of the left sideband harmonic around the $125 \mathrm{~Hz}$ inherent mixed-eccentricity harmonic. Also, the right sideband harmonic close to $75 \mathrm{~Hz}$, due to inherent mixed-eccentricity, is also visible, as well as the left sideband at $50 \mathrm{~Hz}$. Finally, both sidebands of the inherent mixed-eccentricity harmonic close to $25 \mathrm{~Hz}$ are easily noticed.

The MUSIC spectrograms allow identifying some faultrelated signatures unequivocally in the time-frequency plane during the startup transient and the following state-state (see Fig. 15). Two trajectories are born at $50 \mathrm{~Hz}$ and evolve to the $150 \mathrm{~Hz}$ harmonic. These patterns correspond to the $3 \cdot f_{s}-2 \cdot s \cdot f_{s}$ and $3 \cdot f_{s}-4 \cdot s \cdot f_{s}$ sidebands, which display a higher energy as the fault severity increases. The first sideband goes straight from 50 to $150 \mathrm{~Hz}$. The second sideband depicts a trajectory with a V-shape pattern. A third sideband, $3 \cdot f_{s}-6 \cdot s \cdot f_{s}$, appears at steady state in the case of two broken rotor bars. It is also present the lower side band $f_{s}-2 \cdot s \cdot f_{s}$, observable in the phasecurrent spectrum during the startup of line-fed IM with a rotor asymmetry.

Therefore, the fault severity can be evaluated by the number trajectories of fault related harmonics visible in the spectrogram, the portion of these trajectories observable and their color intensity. Table II summarizes the graphic results in a qualitative manner. The greater the fault severity, the bigger the number of fault related harmonics present in the spectrogram. For example, the $3 f s-6 s f s$ and $f s-2 s f s$ are only present when the rotor suffers two broken rotor bars. The visible portion of the fault harmonic trajectory also depends on the fault severity. For example, the full trajectory of the $3 f s-4 s f s$ harmonic is only visible for the maximun full severity and the motor operation at full load. Also the intensity color of the harmonic trajectory changes with the severity of the fault. The colourmap used is called "hot", and as the fault severity increases, the color of the fault related harmonics tend to lighter tones.

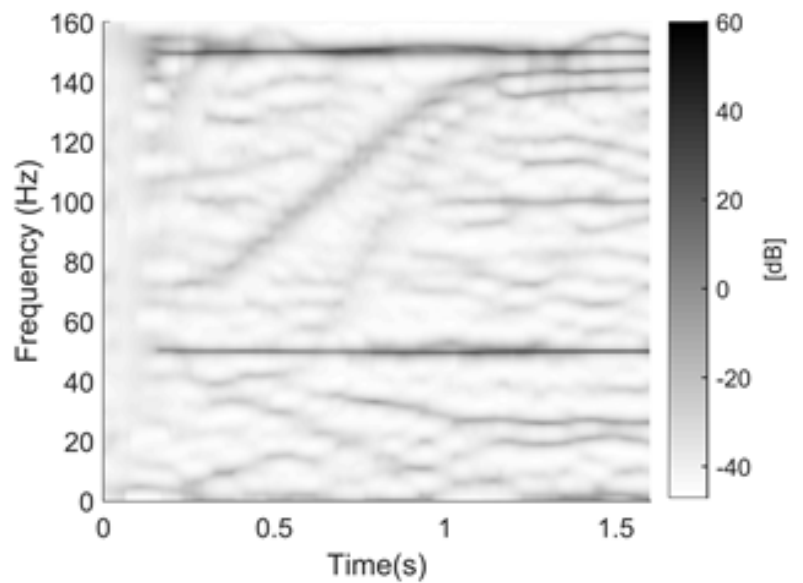

Fig. 13. MUSIC (order 42) spectrogram of the healthy motor and at full load.

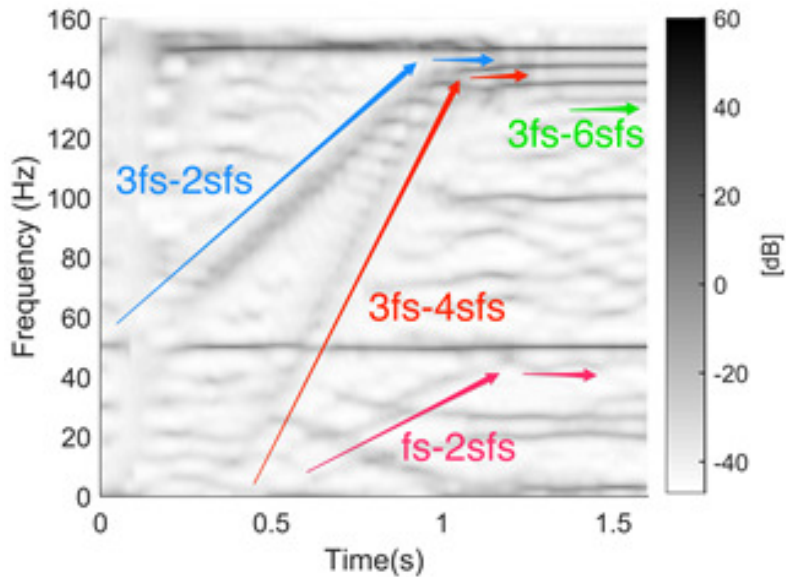

Fig. 14. MUSIC (order 38) spectrogram of the motor with 1 broken rotor bar and at full load.

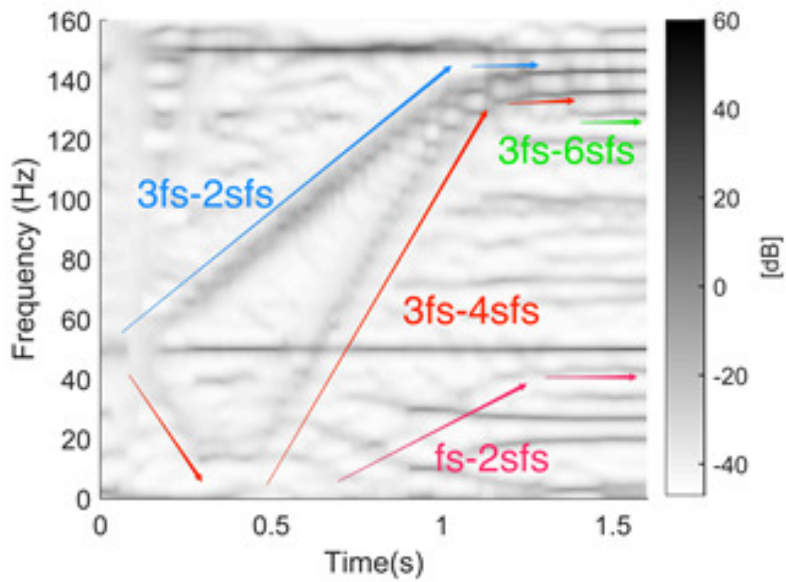

Fig. 15. MUSIC (order 42) spectrogram of the motor with 2 broken rotor bars and at full load. 
TABLE II

FAULT SEVERITY EVALUATION

\begin{tabular}{|c|c|c|c|c|c|}
\hline \multirow{2}{*}{$\begin{array}{c}\text { Fault } \\
\text { Severity }\end{array}$} & \multicolumn{4}{|c|}{ Fault related Harmonics } & \multirow{2}{*}{$\begin{array}{c}\text { Severity } \\
\text { Evaluation }\end{array}$} \\
\hline & $3 f_{s}-2 s f_{s}$ & $3 f_{s}-4 s f_{s}$ & $3 f_{s}-6 s f_{s}$ & $f_{s}-2 s f_{s}$ & \\
\hline \multirow{2}{*}{ Healthy } & $* * *$ & $* *$ & & & $\begin{array}{c}\text { Trajectory } \\
\text { Length }\end{array}$ \\
\hline & $* *$ & $* *$ & & & Intensity \\
\hline \multirow{2}{*}{$1 \mathrm{BRB}$} & $* * * *$ & $* * *$ & $*$ & $* *$ & $\begin{array}{c}\text { Trajectory } \\
\text { Length }\end{array}$ \\
\hline & $* * *$ & $* * *$ & $* * *$ & $* *$ & Intensity \\
\hline \multirow{2}{*}{$2 \mathrm{BRB}$} & $* * * *$ & $* * * *$ & * & $* * *$ & $\begin{array}{c}\text { Trajectory } \\
\text { Length }\end{array}$ \\
\hline & $* * * *$ & $* * * *$ & $* * *$ & **** & Intensity \\
\hline
\end{tabular}

\section{CONCLUSIONS}

In this paper, a novel methodology for the diagnosis of broken rotor bars is presented. The proposed method is based on a high-resolution spectral analysis of the zero sequence current with a multiple signal classification technique. The proposed methodology has been investigated, using motors with very different characteristics, with both Finite Element Simulations and experimentally in a controlled laboratory environment. A line-fed induction motor has been tested at different loads and in three condition states: healthy, with one broken rotor bar and with two broken rotor bars. The Finite Element simulation results were verified by the extensive experimental testing with success.

The ZSC, computed from the three phase currents during the startup, is analyzed with MUSIC, which provides a high spectral resolution during the motor transient and the subsequent steady state as well. This signal, compared to the phase current usually utilized for monitoring purposes, has demonstrated to be very sensitive to the motor condition, even when the motor is at no load or very low load levels. Moreover, for low time transients the ZSC proves to reveal the fault while the traditional analysis of a single stator current is unreliable.

\section{REFERENCES}

[1] H. Henao, G-A. Capolino, M. Fernández-Cabanas, F. Filippetti, C. Bruzzese, E. Strangas, R. Pusca, J. Estima, M. Riera-Guasp, and S.H. $\mathrm{Kia}$, "Trends in Fault Diagnosis for Electrical Machines," IEEE Ind. Electr. Magaz., pp. 31-42, June 2014.

[2] A. Bellini, F. Filippetti, C. Tassoni, and G.-A. Capolino, "Advances in diagnostic techniques for induction machines," IEEE Trans. Ind. Electr., vol. 55, no. 12, pp. 4109-4126, 2008.

[3] M. Riera-Guasp, J.A. Antonino-Daviu, G. A. Capolino, "Advances in Electrical Machine, Power Electronic, and Drive Condition Monitoring and Fault Detection: State of the Art," IEEE Trans. Ind. Electr., vol. 62, no. 3, pp. 1746-1759, Mar. 2015.

[4] W.T. Thomson, M. Fenger, "Current signature analysis to detect induction motor faults" IEEE Ind. Appl. Magaz, pp. 26-34, July/August 2001.

[5] R. R. Schoen and T.G. Habetler. "Evaluation and Implementation of a System to Eliminate Arbitrary Load Effects in Current-Based Monitoring of Induction Machines," IEEE Trans. Ind. Appl., vol. 33, no. 6, pp. 1571-1577, Nov./Dec. 1997.

[6] J. A. Antonino-Daviu, M. Riera-Guasp, J. R. Folch, and M. Pilar Molina Palomares, "Validation of a new method for the diagnosis of rotor bar failures via wavelet transform in industrial induction machines," IEEE Trans. Ind. Appl., vol. 42, pp. 990-996, 2006.

[7] Jongbin Park; Byunghwan Kim; Jinkyu Yang; Sang Bin Lee; Ernesto J. Wiedenbrug; Mike Teska; Seungoh Han, "Evaluation of the detectability of broken rotor bars for double squirrel cage rotor induction motors," 2010 IEEE Energy Conversion Congress and Exposition, Atlanta, GA, 2010, pp. 2493-2500.

[8] S. Lee, J. Hong, S. B. Lee, E. J. Wiedenbrug, M. Teska and H. Kim, "Evaluation of the Influence of Rotor Axial Air Ducts on Condition Monitoring of Induction Motors," in IEEE Transactions on Industry Applications, vol. 49, no. 5, pp. 2024-2033, Sept.-Oct. 2013.

[9] Allianz Insurance, "Monitoring und Diagnose elektrischer Maschinen und Antriebe", Germany (1996-1999), VDE Colloquium, June 28, 2001.

[10] J.M. Cubert, "Use of electronic controllers in order to increase the service life on asynchronous motors", Proc. European seminar on electro-technologies for industry, Bilbao, May 1992, pp.393-404

[11] M. F. Cabanas, M. G. Melero, G. A. Orcajo, J. M. Cano, J. Solares, Maintenance and Diagnostic Techniques for Rotating Electric Machinery, Marcombo Boixareu, 1999.

[12] M. Riera-Guasp, M. Fernández Cabanas, J. Antonino-Daviu, M. Pineda-Sánchez, C. H. Rojas, "Influence of not-Consecutive Bar Breakages in Motor Current Signature Analysis for the Diagnosis of Rotor Faults in Induction Motors", IEEE Trans. Ener. Conv., vol. 25, no.1, pp.80-89, Mar. 2010.

[13] G. Y. Sizov, A. Sayed-Ahmed, Y. Chia-Chou, and N. A. O. Demerdash, "Analysis and diagnostics of adjacent and nonadjacent broken rotor bar faults in squirrel-cage induction machines," IEEE Trans. Ind. Electr., vol. 56, no. 11, pp. 4627-4641, Nov. 2009.

[14] S.B. Lee, E. Wiedenbrug., K. Younsi, "ECCE 2013 Tutorial: Testing and Diagnostics of Induction Machines in an Industrial Environment," presented at ECCE 2013, Denver, CO, USA, Sep 2013.

[15] W. R. Finley, M. M. Hodowanec, W. G. Holter, "Diagnosing Motor Vibration Problems", Pulp and Paper Industry Technical Conference, 2000. Conference Record of 2000 Annual, 2000, pp. 165 - 180.

[16] J. S. Hsu, "Monitoring of defects in induction motors through air-gap torque observation," IEEE Trans. Ind. Appl., vol. 31, no. 5, pp. 10161021, Sep./Oct. 1995.

[17] V. V. Thomas, K. Vasudevan, and V. J. Kumar, "Online cage rotor fault detection using air-gap torque spectra," IEEE Trans. Ener. Conv., vol. 18, no. 2, pp. 265-270, Jun. 2003.

[18] M.N. Uddin,W. Wang, Huang Zhi Rui, "Modeling and Minimization of Speed Ripple of a Faulty Induction Motor With Broken Rotor Bars," IEEE Transactions on Industry Applications, vol. 46, no.6, pp.22432250, Nov.-Dec. 2010

[19] R. Romary, R. Pusca, J. P. Lecointe, and J. F. Brudny, "Electrical machines fault diagnosis by stray flux analysis," in Proc. IEEE Workshop Electrical Machines Design, Control and Diagnosis (WEMDCD’2013), Paris, France, Mar. 11-12, pp. 245-254.

[20] J. Penman, M. N. Dey, A. J. Tait and W. E. Brian, "Condition monitoring of electrical drives," IEE Proc., Part B, vol. 133, no. 3, pp. 142-148, May 1986.

[21] S. H. Kia, H. Henao, G. A. Capolino and C. Martis, "Induction Machine Broken Bars Fault Detection Using Stray Flux after Supply Disconnection," IEEE $32^{\text {nd }}$ IECON, pp. 1498-1503, Paris, France, Nov. 2006.

[22] M. Eltabach, A. Charara, and I. Zein, "A comparison of external and internal methods of signal spectral analysis for broken rotor bars detection in induction motors," IEEE Trans. Ind. Electr., vol. 51, no. 1, pp. 107-121, Feb. 2004.

[23] M. Drif and A. J. M. Cardoso, "Discriminating the Simultaneous Occurrence of Three-Phase Induction Motor Rotor Faults and Mechanical Load Oscillations by the Instantaneous Active and Reactive Power Media Signature Analyses," IEEE Trans. Ind. Elec., vol. 59, no. 3, pp. 1630-1639, 2012.

[24] J.D. Gierlach, "Using Ultrasound To Identify Electrical Faults", Maintenance Technology, Jan. 2013.

[25] R. Romero-Troncoso, "Multirate Signal Processing to Improve FFTbased Analysis for Detecting Faults in Induction Motors," in IEEE Transactions on Industrial Informatics, vol.PP, no.99, pp.1-1.

[26] V. Ghorbanian J. Faiz "A survey on time and frequency characteristics of induction motors with broken rotor bars in line-start and inverter-fed modes", Mech. Syst. Signal Processing, vol. 54 pp. 427-456 Mar. 2015.

[27] A. J. M. Cardoso, S. M. A. Cruz, J. F. S. Carvalho and E. S. Saraiva, "Rotor Cage Fault Diagnosis in Three-Phase Induction Motors, by Park's Vector Approach," Conference Record of the Thirtieth IAS Annual Meeting, IAS '95, vol. 1, pp. 642-646, Orlando, FL, Oct. 1995. 
[28] S. M. A. Cruz and A. J. M. Cardoso, "Rotor cage fault diagnosis in three-phase induction motors by extended Park's vector approach," Elec. Mach. Power Syst., vol. 28, no. 4, pp. 289-299, 2000.

[29] B. Xu, L. Sun, L. Xu, G. Xu, "Improvement of the Hilbert Method via ESPRIT for Detecting Rotor Fault in Induction Motors at Low Slip“, IEEE Trans. Ener. Conv., vol. 28, no. 1, pp. 225-233, March 2013.

[30] Y. Gritli,C. Rossi ; L. Zarri ; F. Filippetti ; A. Chatti ; D. Casadei ; A. Stefani, "Advanced diagnosis of broken bar fault in induction machines by using Discrete Wavelet Transform under time-varying condition," 2011 IEEE International Electric Machines \& Drives Conference (IEMDC), Niagara Falls, ON, 2011, pp. 424-429.

[31] F. Briz, M. W. Degner, P. Garcia, and D. Bragado, "Broken rotor bar detection in line-fed induction machines using complex wavelet analysis of startup transients," IEEE Trans. Ind. Appl., vol. 44, no. 3, pp. 760-768, May/Jun. 2008.

[32] R. Supangat, N. Ertugrul, W. L. Soong, D. A. Gray, C. Hansen, and J. Grieger, "Detection of broken rotor bars in induction motor using starting-current analysis and effects of loading," IEE Proc. Electr. Power Appl., vol. 153, no. 6, pp. 848-855, Nov. 2006.

[33] Z.K. Peng, P.W. Tse, F.L. Chu, "A Comparison Study of Improved Hilbert-Huang Transform and Wavelet Transform: Application to Fault Diagnosis for Rolling Bearing", Mechanical Systems and Signal Processing, Elsevier, vol. 19, 2005, pp. 974-988.

[34] J. Faiz, V. Ghorbanian and B. M. Ebrahimi, "EMD-Based Analysis of Industrial Induction Motors With Broken Rotor Bars for Identification of Operating Point at Different Supply Modes," in IEEE Transactions on Industrial Informatics, vol. 10, no. 2, pp. 957-966, May 2014.

[35] V. Climente-Alarcon, J.A. Antonino-Daviu, M. Riera-Guasp, M. Vlcek, "Induction Motor Diagnosis by Advanced Notch FIR Filters and the Wigner-Ville Distribution," IEEE Transactions on Industrial Electronics, vol.61, no.8, pp.4217,4227, Aug. 2014

[36] K.N. Gyftakis, J.A. Antonino-Daviu, R. Garcia-Hernandez, M. McCulloch, D.A. Howey, A.J.M. Cardoso, "Comparative Experimental Investigation of the Broken Bar Fault Detectability in Induction Motors," IEEE Trans. Ind. Appl., vol. 52, no. 2, pp. 14521459, 2016

[37] K.N. Gyftakis and J. Kappatou, "The Zero-Sequence Current Spectrum as an On-Line Static Eccentricity Diagnostic Mean in $\Delta$-Connected PSH-Induction Motors", IEEE SDEMPED'13, Valencia, Spain, 27-30 Aug. 2013.

[38] K. N. Gyftakis and J. Kappatou, "The Zero-Sequence Current as a Generalized Diagnostic Mean in $\Delta$-Connected Induction Motors," IEEE Trans. Ener. Conv., vol. 29, no. 1, pp. 138-148, Mar. 2014.

[39] D. Morinigo-Sotelo, R. J. Romero-Troncoso, J. A. Antonino-Daviu and K. N. Gyftakis, "Reliable detection of broken rotor bars in induction motors via MUSIC and ZSC methods," 2016 XXII International Conference on Electrical Machines (ICEM), Lausanne, 2016, pp. 2881-2886.

[40] S.H. Kia, H. Henao, and G.A. Capolino, "A High-Resolution Frequency Estimation Method for Three-Phase Induction Machine Fault Detection," IEEE Trans. Ind. Electr., vol. 54, no. 4, pp. 23052314, Aug. 2007.

[41] R.J. Romero-Troncoso, A. Garcia-Perez, D. Morinigo-Sotelo, O. Duque-Perez, R.A. Osornio-Rios and M.A. Ibarra-Manzano, "Rotor unbalance and broken rotor bar detection in inverter-fed induction motors at start-up and steady-state regimes by high-resolution spectral analysis," Electric Power Systems Research, vol. 133, pp. 142-148, April, 2016.

[42] R. Schmidt, "Multiple emitter location and signal parameter estimation," RADC Spectral Estimation Workshop, Rome, NY, pp. 243-258, 1979.

[43] G. Bienvenu and L. Kopp, "Optimality of high resolution array processing using the eigensystem approach," IEEE. Trans. Acous, Speech Signal Proc., vol. 31, no. 5, pp. 1235-1248, Oct., 1983.

[44] F. Filippetti, G. Franceschini, C. Tassoni and P. Vas, "AI Techniques in Induction Machines Diagnosis Including the Speed Ripple Effect", IEEE Trans. Ind. Appl., Vol. 34, No. 1, pp. 98-108, Jan./Feb. 1998.

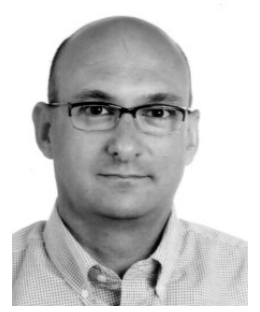

\section{BIOGRAPHIES}

Daniel Morinigo-Sotelo received the B.S.and $\mathrm{Ph} . \mathrm{D}$. degrees in electrical engineering from the University of Valladolid (UVA), Spain, in 1999 and 2006, respectively. He was a Research
Collaborator on Electromagnetic Processing of Materials with the Light Alloys Division of CIDAUT Foundation since 2000 until 2015. He is currently with the Research Group in Predictive Maintenance and Testing of Electrical Machines, Department of Electrical Engineering, UVA and with the HSPdigital Research Group, México. His current research interests also include condition monitoring of induction machines, optimal electromagnetic design, and heuristic optimization.

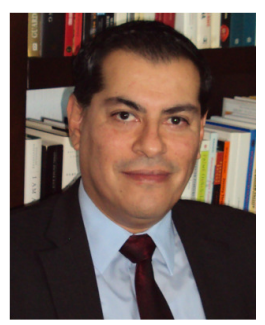

Rene de J. Romero-Troncoso (M'07-SM'12) received the $\mathrm{Ph} . \mathrm{D}$. degree in mechatronics from the Autonomous University of Queretaro, Mexico, in 2004. He is a National Researcher level 3 with the Mexican Council of Science and Technology, CONACYT, and Fellow of the Mexican Academy of Engineering. He is currently a Head Professor with the University of Guanajuato and he has been an Invited Researcher with the Autonomous University of Queretaro, Mexico, and with the University of Valladolid, Spain. He is author of two books on digital systems (in Spanish), and a coauthor of more than 170 technical papers published in international journals and conferences. His fields of interest include hardware signal processing with FPGA and monitoring and diagnosis on dynamic systems. Dr. Romero-Troncoso was a recipient of the 2004 Asociación Mexicana de Directivos de la Investigación Aplicada y el Desarrollo Tecnológico Nacional Award on Innovation for his work in applied mechatronics, and the 2005 IEEE ReConFig Award for his work in digital systems. He is part of the editorial board of Hindawi's International Journal of Manufacturing Engineering.

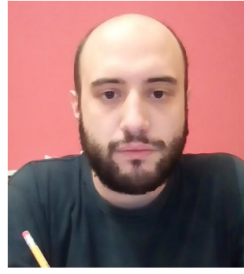

Panagiotis A. Panagiotou was born in Thessaloniki, Greece, in June 1989. He received the Diploma in Electrical and Computer Engineering from the University of Patras, Greece in 2015. Since 2016 he has been a Ph.D Candidate with the Research Centre for Mobility and Transport, Coventry University, UK. His research is focused on condition monitoring and fault diagnosis of electric motors for EV applications, as well as statistical modelling and signal processing for diagnostic purposes.

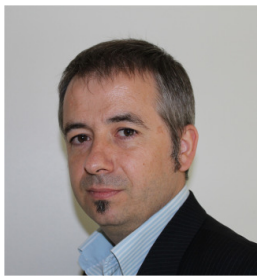

Jose A. Antonino-Daviu (SM'12) received his M.S. and $\mathrm{Ph}$. D. degrees in Electrica Engineering, both from the Universitat Politècnica de València, in 2000 and 2006 respectively. $\mathrm{He}$ also received his Bs. in Business Administration from Universitat de Valencia in 2012. He was working for IBM during 2 years, being involved in several international projects. Currently, he is Associate Professor in the Department of Electrical Engineering of the mentioned University, where he develops his docent and research work. He has been invited professor in Helsinki University of Technology (Finland) in 2005 and 2007, Michigan State University (USA) in 2010, Korea University (Korea) in 2014 and Université Claude Bernard Lyon 1 (France) in 2015. $\mathrm{He}$ is IEEE Senior Member since 2012 and he has published over 100 contributions, including international journals, conferences and books.

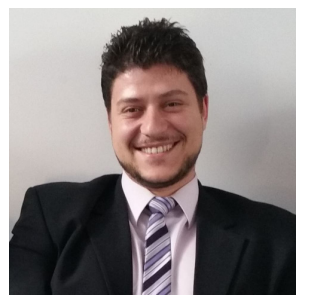

Konstantinos N. Gyftakis (M'11) was born in Patras, Greece, in May 1984. He received the Diploma in Electrical and Computer Engineering from the University of Patras, Patras, Greece in 2010. He pursued a Ph.D in the same institution in the area of electrical machines condition monitoring and fault diagnosis (2010-2014). Then he worked as a Post-Doctoral Research Assistant in the Dept. of Engineering Science, University of Oxford, UK (2014-2015). He is currently a Lecturer, School of Computing, Electronics and Mathematics, Faculty of Engineering, Environment and Computing and an associate with the Research Centre for Mobility and Transport, Coventry University, UK. His research activities are in fault diagnosis, condition monitoring and degradation of electrical machines. He has authored/co-authored more than 50 papers in international scientific journals and conferences. (E-mail: k.n.gyftakis@ieee.org). 
